\title{
The Proteasome Inhibitor Bortezomib Prevents Lupus Nephritis in the NZB/W F1 Mouse Model by Preservation of Glomerular and Tubulointerstitial Architecture
}

\author{
Nadine Hainz ${ }^{a}$ Susanne Thomas ${ }^{a}$ Kirsten Neubert $^{b, e}$ Silke Meister ${ }^{b}$, \\ Kerstin Benz ${ }^{c}$ Manfred Rauh ${ }^{c}$ Christoph Daniela Michael Wiesener ${ }^{d}$ e \\ Reinhard E. Voll ${ }^{b}$ e Kerstin Amann ${ }^{a}$ \\ ${ }^{a}$ Nephropathology, Department of Pathology, ${ }^{b}$ Rheumatology and Clinical Immunology, Department of \\ Internal Medicine 3, 'Department of Pediatrics, ${ }^{\mathrm{d}}$ Department of Nephrology and Hypertension, and \\ eNikolaus-Fiebiger-Center of Molecular Medicine, University of Erlangen-Nürnberg, Erlangen, Germany
}

\section{Key Words}

Proteasome inhibition $\cdot$ Autoimmune disease $\cdot$ Systemic

lupus erythematosus $\cdot$ Podocyte $\cdot$ Proteinuria

\begin{abstract}
Background/Aims: Crucial steps in the initiation of lupus nephritis are the deposition of (auto-)antibodies and consequent complement activation. In spite of aggressive treatment patients may develop terminal renal failure. Therefore, new treatment strategies are needed. In extension to our previously published data we here analyzed the potential renoprotective mechanisms of bortezomib (BZ) in experimental lupus nephritis by focusing on morphological changes. Methods: Female NZB X NZW F1 mice develop lupus-like disease with extensive nephritis that finally leads to lethal renal failure. Treatment with $0.75 \mathrm{mg} / \mathrm{kg}$ BZ i.v. or placebo (PBS) twice per week started at 18 or 24 weeks of age. Antibody production was measured with ELISA and kidney damage was determined by quantitative morphological and immunohistochemical methods. Results: BZ treatment completely inhibited antibody production in both BZ-treated groups and prevented the development of nephritis in comparison to PBS-treated animals. Glomerular and tubulointer-
\end{abstract}

\section{KARGER}

Fax +41613061234 E-Mail karger@karger.ch www.karger.com

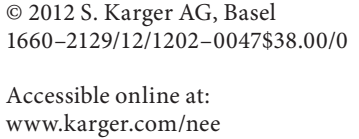

stitial damage scores, collagen IV expression, mean glomerular volume as well as tubulointerstitial proliferation and apoptosis were significantly lower after BZ treatment. Glomerular ultrastructure and in particular podocyte damage and loss were prevented by BZ treatment. Conclusions: BZ effectively prevents the development of nephritis in the NZB/W F1 mouse model. Specific protection of podocyte ultrastructure may critically contribute to renoprotection by $B Z$, which may also represent a potential new treatment option in human lupus nephritis.

Copyright $\odot 2012$ S. Karger AG, Basel

\section{Introduction}

Systemic lupus erythematosus (SLE) represents a prototypic systemic autoimmune disease affecting multiple organs, particularly the kidney $[1,2]$. The treatment of renal disease in SLE remains a serious clinical challenge, in particular in adolescent or young patients. Despite aggressive treatments including high-dose glucocorticoid

N. Hainz and S. Thomas contributed equally to the paper.
Prof. Dr. Kerstin Amann

Department of Pathology, Nephropathology

Krankenhausstrasse 8-10

DE-91054 Erlangen (Germany)

Tel. +49 9131852 2291, E-Mail kerstin.amann@uk-erlangen.de 
and cyclophosphamide or mycophenolate mofetil, remissions are frequently of short duration or sometimes cannot be achieved at all. Recently, new treatment options for SLE patients with refractory renal disease have been suggested, i.e. anti-CD20 antibodies, immunoadsorption, and high-dose chemotherapy with autologous stem cell transplantation. However, these treatments are accompanied by serious side effects, high treatment costs or not yet established efficacy.

In SLE patients as well as NZB/W F1 lupus mice [3-6], IgG autoantibodies against double-stranded (ds) DNA, nucleosomes, phospholipids, blood cells and other targets are crucially involved in the pathogenesis of renal lesions and hematological manifestations. In up to $60 \%$ of patients lupus nephritis is the first organ manifestation of SLE. In NZB/W F1 lupus mice renal disease usually starts at the age of 5-7 months with proteinuria and thereafter progresses leading to death of the animals at a mean age of 8-9 months [6-8].

Whereas the above-mentioned current treatments efficiently attack B lymphocytes, plasmablasts and shortlived plasma cells, long-lived plasma cells are resistant [4]. There is evidence that a substantial number of long-lived plasma cells can survive even autologous and allogeneic stem cell transplantations $[9,10]$.

The selective inhibitor of the $26 \mathrm{~S}$ proteasome bortezomib (BZ) is approved for the treatment of relapsed multiple myeloma $[11,12]$. The proteasome is a multienzymatic protein complex that is indispensable in cell homeostasis. Its functions include degradation of un- or misfolded proteins, control of cell cycle, regulation of gene expression and activation of NF- $\mathrm{KB}$. Consequently, mechanisms of BZ action include inhibition of NF- $\kappa \mathrm{B}$, modulation of the tumor microenvironment, cytokine expression and stroma cell interactions [13-15]. In addition, we and others recently demonstrated that proteasome inhibition induces cell death due to activation of the terminal unfolded protein response (UPR), especially in cells with high immunoglobulin synthesis $[13,16]$. Therefore, $\mathrm{BZ}$ is also a new treatment option in autoimmune disease when pathogenicity is mediated by antibodies.

In a previous study, we described a remarkable systemic and also renoprotective effect of $\mathrm{BZ}$ in the NZB/W F1 model of SLE focusing on the basic immunological mechanisms. We could show that BZ eliminates both short- and long-lived plasma cells by activation of the UPR. In addition, treatment with BZ-depleted plasma cells produced antibodies to dsDNA and prolonged the survival of two mouse strains with lupus-like disease, NZB/W F1 and MRL/lpr mice [17].

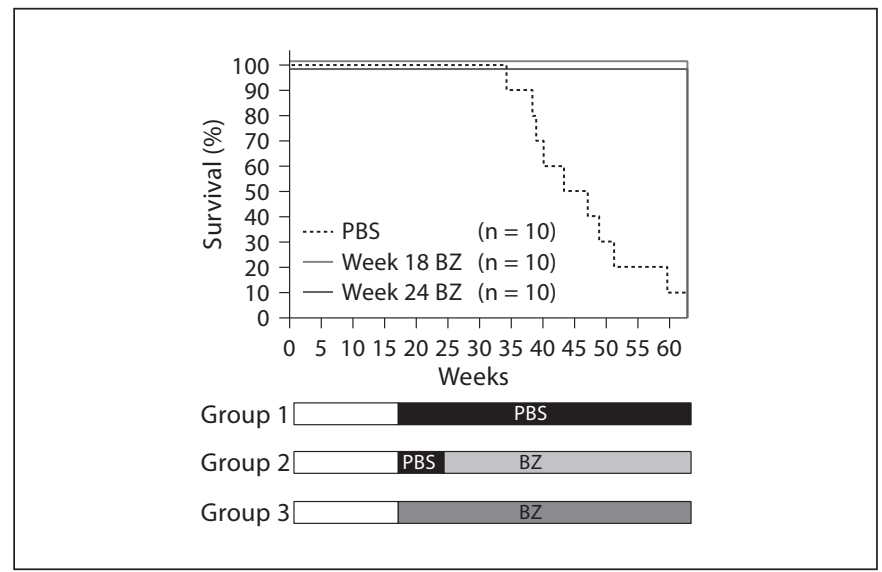

Fig. 1. Survival of NZB/W F1 mice after treatment with BZ. Ten NZB/W F1 mice per group were either treated with PBS (black dotted line) or BZ starting week 18 (light gray line) or week 24 (dark gray line). Mortality of PBS-treated NZB/W F1 mice was significantly higher compared to BZ-treated NZB/W F1 mice (log-rank Mantel-Cox test, $\mathrm{p}<0.004)$.

Since morphometric analyses and potential kidneyspecific effects contributing to the renoprotection by BZ were not addressed in the previous study, we here performed detailed morphological analyses including electron microscopy as well as measurements of kidney function. In the present study, we show that BZ treatment in experimental lupus nephritis ameliorate kidney function by preserving glomerular and tubulointerstitial architecture including prevention of podocyte damage.

\section{Materials and Methods}

\section{Animal Model}

NZB/W F1 female mice and BALB/c mice were purchased from Jackson Laboratories and Harlan Winkelmann and maintained in the animal facilities of the Fiebiger Center for Molecular Medicine. NZB/W F1 mice spontaneously develop a disease closely resembling human SLE [6], in particular the mice develop proliferative nephritis which is very similar to human proliferative lupus nephritis (WHO IV, ISN/RPS IV).

To investigate the therapeutic effect of BZ in an autoantibodymediated disease we treated NZB/W F1 mice twice weekly $(0.75$ $\mathrm{mg} / \mathrm{kg}$ body weight BZ i.v., Janssen-Cilag, Germany) for a period of 10 and 8.5 months. In the first group, BZ treatment was started before the onset of proteinuria at the age of 18 weeks $(n=10)$. The second group was treated with PBS at the age of 18 weeks followed by $\mathrm{BZ}$ treatment at the age of 24 weeks when proteinuria was detectable in NZB/W F1 mice $(\mathrm{n}=10)$. The control group $(\mathrm{n}=10)$ was i.v. injected with PBS beginning at the age of 18 weeks (fig. 1) [17]. 
According to governmental regulations of animal protection, severely diseased, premortal animals as judged by institutional criteria including behavior, posture, piloerection, breathing, exophthalmus and reflexes were euthanized. Only 2 PBS-treated $\mathrm{NZB} / \mathrm{W}$ F1 mice were found dead in the cage and had to be excluded from morphological analysis.

\section{Biochemistry}

Serum and Urine Parameters

Development and progression of kidney disease in NZB/W F1 mice was assessed monthly from the age of 7 months onwards by placing the mice individually in metabolic cages for $24 \mathrm{~h}$. Proteinuria as parameter for renal injury was analyzed by semiquantitative colorimetric measurement using Albustix ${ }^{\circledR}$ (Bayer) and quantitative measurement using a pyrogallol-red/molybdate photometric assay was only performed at weeks 30,34 and 38 when $90 \%$ of the PBS-treated NZB/W F1 mice were still alive. Mice with proteinuria $\geq 200 \mathrm{mg} / \mathrm{dl}$ in repeated analyses were regarded as proteinuria positive. At the end of the experiment blood was taken and analyzed for serum urea using an enzymatic approach (Roche Integra 800 and appropriate system reagents).

\section{ELISA Assays}

The concentrations of IgG antibodies in the sera were determined by a sandwich ELISA. Nunc-Immuno 96 well Maxisorp ELISA plates were coated with $1 \mu \mathrm{g} / \mathrm{ml}$ goat anti-mouse IgG (Southern Biotechnologies) overnight at $4^{\circ} \mathrm{C}$. After blocking the plates with $2 \%$ FCS in PBS, diluted serum samples were added in triplicates. Bound IgG was detected with horseradish peroxidaseconjugated goat anti-mouse IgG (Southern Biotech, USA). The IgG concentrations were calculated from a standard curve obtained using purified mouse IgG (Jackson Immuno Research).

Antibodies to dsDNA were quantified as previously described [18]. Briefly, ELISA plates were precoated with $20 \mu \mathrm{g} / \mathrm{ml}$ poly-Llysine (Sigma) overnight at $4^{\circ} \mathrm{C}$, followed by incubation with 20 $\mu \mathrm{g} / \mathrm{ml}$ of calf thymus DNA (Sigma) overnight at $4^{\circ} \mathrm{C}$. After blocking with 2\% FCS in PBS, sera were diluted 1:200 in blocking buffer and incubated for $2 \mathrm{~h}$ at ambient temperature. Bound IgG was detected with horseradish peroxidase-conjugated goat antimouse IgG (Southern Biotech).

\section{Morphologic Evaluation}

For histological analyses, kidneys were carefully harvested, total organ weight was determined and kidneys were fixed in paraformaldehyde. Kidneys were then dissected in 1-mm-thick slices perpendicular to the longitudinal axis. Tissue sampling for morphometric and stereological analysis was performed using the area weighted sampling technique as described [19]. The kidney slices were embedded in paraffin; 2 - $\mu \mathrm{m}$-thick paraffin sections as well as $1-\mu \mathrm{m}$-thick semithin sections ( 5 blocks per animal) were cut and stained with hematoxylin-eosin, periodic acid Schiff (PAS), Sirius red (fibrous tissue stain) or methylene blue (semithin sections). Renal morphology was investigated by light microscopy (various magnifications) as described below with the investigator being blinded to the treatment groups. For qualitative electron microscopy several ultrathin sections $(0.08 \mu \mathrm{m})$ per animal were prepared and stained with uranyl acetate/lead citrate.

The degree of mesangial matrix expansion and glomerular sclerosis (glomerulosclerosis index, GSI) was determined on PASstained paraffin sections adopting the semiquantitative scoring systems proposed by el Nahas et al. [20] and Goumenos et al. [21]. Using light microscopy at a magnification of $\times 400$, the glomerular score of each animal was derived as the mean of 100 randomly sampled glomeruli. The severity of glomerulosclerosis was expressed on an arbitrary scale from 0 to 4 . The glomerular score for individual glomeruli was: grade 0 , normal glomerulus; grade 1 , presence of mesangial expansion/thickening of the basement membrane; grade 2, mild/moderate segmental hyalinosis/sclerosis involving less than $50 \%$ of the glomerular tuft; grade 3 , diffuse glomerular hyalinosis/sclerosis involving more than $50 \%$ of the tuft, and grade 4, diffuse glomerulosclerosis with total tuft obliteration and collapse [22].

Mesangiolysis is associated with loss of mesangial cells, capillary dilatation and finally formation of capillary aneurysms. Mesangiolysis was assessed in PAS-stained paraffin sections and graded in 100 systematically subsampled glomeruli per animal using the following scoring system (MSI): score 0 , no changes of capillaries; score 1, capillary dilatation $<25 \%$ of glomerular tuft area; score 2 , capillary dilatation $>25 \%$ of glomerular tuft area or capillary aneurysm $<50 \%$ of glomerular tuft area; score 3 , capillary aneurysm comprising $50-75 \%$ of glomerular tuft area, and score 4 , capillary aneurysm comprising $>75 \%$ of glomerular tuft area. The resulting index in each animal was expressed as a mean of all scores obtained.

Tubulointerstitial damage, i.e. tubular atrophy, tubular dilatation, interstitial fibrosis and interstitial inflammation, was assessed on PAS-stained paraffin sections at a magnification of $\times 100$ using a semiquantitative scoring system (tubulointerstitial lesion score, TSI). For determination of TSI, 10 fields per kidney were randomly sampled and graded as follows: grade 0 , no change; grade 1 , lesions involving less than $25 \%$ of the area; grade 2 , lesions affecting 25-50\%; grade 3, lesions involving more than $50 \%$, and grade 4 involving (almost) the entire area.

Vascular lesions (VSI) in each kidney were attributed grades of severity from 0 to 4 in 10 fields at $\times 200$ magnification. These grades were based on both the severity of vascular wall thickening and the extent of fibrinoid necrosis in afferent arterioles, interlobular arterioles and small arteries. Grade 0 denoted a normal vessel; grade 1 a mild vascular wall thickening; grade 2 a moderate thickening; grade 3 a severe thickening (onion skin pattern), and grade 4, fibrinoid necrosis. The vascular lesion score was obtained using the same procedure as described above.

For determination of pathological changes typical for lupus nephritis we used the Index for Chronicity and Activity according to Austin et al. [23]. For the activity index endocapillaries hypercellularity, leukocyte infiltration, subendothelial hyaline deposits, fibrinoid necrosis, cellular crescents and interstitial inflammation were assessed. For the chronicity index glomerular sclerosis, fibrous crescents, tubular atrophy and interstitial fibrosis were assessed according to Austin et al. [23].

\section{Immunohistochemistry}

Immunohistochemical analyses of paraffin-embedded kidney sections were performed as previously described [19] using the following antibodies: PCNA (1:500, DAKO Diagnostika, Hamburg, Germany); MECA 32 (1:5, supernatant from hybridoma); F4-80 (1:100, Serotec); p27 (1:400, Santa Cruz, USA); WT-1 (1:400, Santa Cruz), nephrin (1:100, Acris, USA); collagen IV (1:100, Southern Biotech); NF-кBp65 (1:100, Santa Cruz); IgG (1:1,000, Vector, USA) and activated (cleaved) caspase-3 (1:100, 
Table 1. Animal data

\begin{tabular}{|c|c|c|c|c|}
\hline & \multicolumn{3}{|l|}{$\mathrm{NZB} / \mathrm{W}$} & \multirow{2}{*}{$\begin{array}{l}\text { Kruskal-Wallis } \\
\text { H test }\end{array}$} \\
\hline & PBS & week $18 \mathrm{BZ}$ & week $24 \mathrm{BZ}$ & \\
\hline Body weight & $39.4 \pm 3.9$ & $39.2 \pm 2.91$ & $39.0 \pm 5.45$ & n.s. \\
\hline Kidney/body weight ratio (mg/g) & $6.9 \pm 1.0$ & $6.8 \pm 0.5$ & $6.5 \pm 0.3$ & n.s. \\
\hline $\begin{array}{l}\text { Relative anti-dsDNA IgG antibody level } \\
\text { at the end of the study }\left(\mathrm{OD}_{495 \mathrm{~nm}}\right)\end{array}$ & $0.97 \pm 0.31$ & $0.08 \pm 0.6^{*}$ & $0.08 \pm 0.07^{*}$ & $\mathrm{p}<0.01$ \\
\hline
\end{tabular}

${ }^{*} \mathrm{p}<0.01$ vs. PBS-treated NZB/W using Dunn's multiple comparison posthoc test.

Chemicon International Inc., USA). Staining localization and intensity of WT-1, nephrin, NF-кBp65 and IgG were qualitatively analyzed on paraffin sections using a scoring system from 0 to 4 . The numbers of p27, activated (cleaved) caspase-3 and PCNApositive cells per glomerulus, tubuli and interstitial area were counted. Collagen IV expression was analyzed per glomerular and tubulointerstitial area using a semiautomatic image analysis system (Analysis, SIS, Münster, Germany).

\section{Analysis of Glomerular Cells and Capillaries Using Semithin} Sections

Glomerular cell number and volume as well as volume density of mesangial matrix were analyzed in semithin sections with a 100 -point eyepiece for point counting at a magnification of $\times 1,000$ (oil immersion) as previously described [19]. Glomerular cell numbers (podocytes, mesangial cells, and endothelial cells) were calculated in at least 30 glomeruli for each animal, from cell density per volume $\left(\mathrm{Nc}_{\mathrm{V}}\right)$ and volume density of the respective cell type $\left(\mathrm{Vc}_{\mathrm{V}}\right)$ according to the formula $\mathrm{Nc}_{\mathrm{V}}=\mathrm{\kappa} / \beta \times \mathrm{Nc}_{\mathrm{A}}{ }^{1.5} / \mathrm{Vc}_{\mathrm{V}}{ }^{0.5}$, with $\kappa=1$ and $\beta=1.5$ for podocytes and $\beta=1.4$ for mesangial and endothelial cells [19]. The respective cell volumes were calculated according to the equation $\mathrm{V}_{\mathrm{c}}=\mathrm{Vc}_{\mathrm{V}} \times \mathrm{V}_{\text {glom }}$. The length density $\left(\mathrm{L}_{\mathrm{V}}\right)$ of glomerular capillaries, i.e. the length of all capillaries per volume of the glomerular tuft, was analyzed as a 3-dimensional parameter of glomerular capillarization according to the standard stereological formula $L_{V}=2 Q_{A}$, with $Q_{A}$ being the number of capillary transects per area of the glomerular tuft [19].

All morphological analyses were done in a blinded fashion, i.e. the investigator was unaware of which group the animal belonged to.

\section{Statistical Analysis}

Data in tables are presented as mean \pm SD and graphs showing box plots with mean, 25th to 75th percentile and whiskers with minimum and maximum. For statistical analysis of differences between the treatment groups the Kruskal-Wallis $\mathrm{H}$ test for non-normally distributed variables and Dunn's multiple comparison test as a posthoc test was used. A p value $<0.05$ was considered statistically significant. Survival of mice is shown in a Kaplan-Meyer graph using the log-rank Mantel-Cox test for comparison.

Data analysis was performed using the GraphPad Prism (GraphPad Software Inc., La Jolla, Calif., USA).

\section{Results}

\section{BZ Lowers Anti-dsDNA Antibodies and Improves Parameters of Renal Function}

As expected, most PBS-treated NZB/W F1 mice developed high amounts of anti-dsDNA antibodies at the age of 6 months which remained high during their lifetime (table 1). In all BZ-treated mice anti-dsDNA antibody titers either remained within the range or decreased to the range of nonautoimmune mice (data not shown). By the age of 15 months only 1 out of 10 PBS-treated NZB/W F1 mice was alive, whereas all $20 \mathrm{BZ}$-treated mice survived (fig. 1). Remarkably, all BZ-treated mice remained healthy without obvious signs of disease or toxicity as shown previously [17]. Of note, there was no difference in body weight or in the kidney/body weight ratio between all 3 groups (table 1).

Serum creatinine and urea as systemic markers of renal function were significantly lower in both BZ-treated groups (fig. 2b, c). When we examined the course of renal disease in NZB/W F1 mice by monthly assessment of proteinuria we found that none of the BZ-treated mice developed marked proteinuria. In contrast, at 34 weeks of age PBS-treated NZB/W F1 mice had developed proteinuria which rose to six times higher in mean at week 38 compared to BZ-treated mice (fig. 2a).

\section{BZ-Treatment Markedly Improves Renal Pathology of NZB/W F1 Mice \\ Pathological changes in PBS-treated mice, as shown by} PAS staining, were ameliorated in BZ-treated mice. Segmental sclerosis and matrix expansion were strongly advanced in PBS-treated mice but were not present in BZtreated mice (fig. 3a, b).

Renal pathology revealed severe glomerular (fig. 4a) and mild to moderate tubulointerstitial damage in all 8 


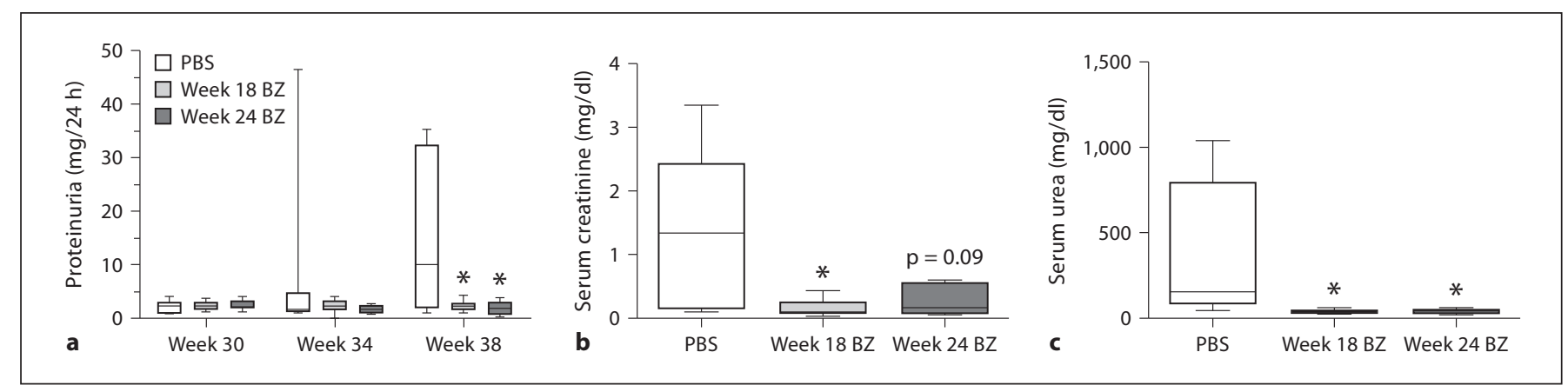

Fig. 2. Physiological markers of renal function. Loss of kidney function in PBS-treated NZB/W F1 mice was documented by measurement of proteinuria in weeks 24-34 (a), serum creatinine (b) and serum urea (c) at the end of the experiment. In NZB/W F1 mice the increase of all 3 parameters was prevented by BZ therapy starting either week 18 and in most cases also week $24 .{ }^{*}$ Statistically significant differences between PBS- and BZ-treated groups $(\mathrm{p}<0.05)$.
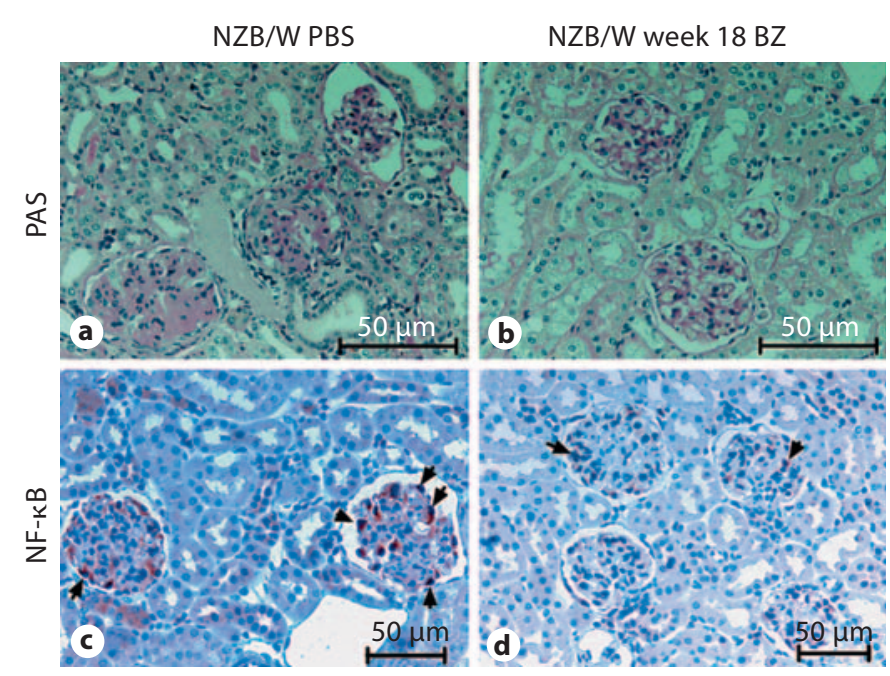

Fig. 3. Histopathological changes in NZB/W F1 mice treated with $\mathrm{BZ}$ compared to PBS treatment. Representative renal morphology of PBS-treated (a) and BZ-treated NZB/W F1 mice (b) at the end point (week 38) using PAS staining of paraffin-embedded sections is shown. Note marked glomerular and tubulointerstitial alterations in PBS-treated NZB/W F1 mice, which are completely prevented by $B Z$ treatment. NF- $\kappa$, as assessed by immunohistological staining (red-brown staining, arrows), was clearly detected in nuclei of PBS-treated (c) but rarely found in BZ-treated (d) NZB/W F1 mice. Preservation of podocytes was investigated by the ex-
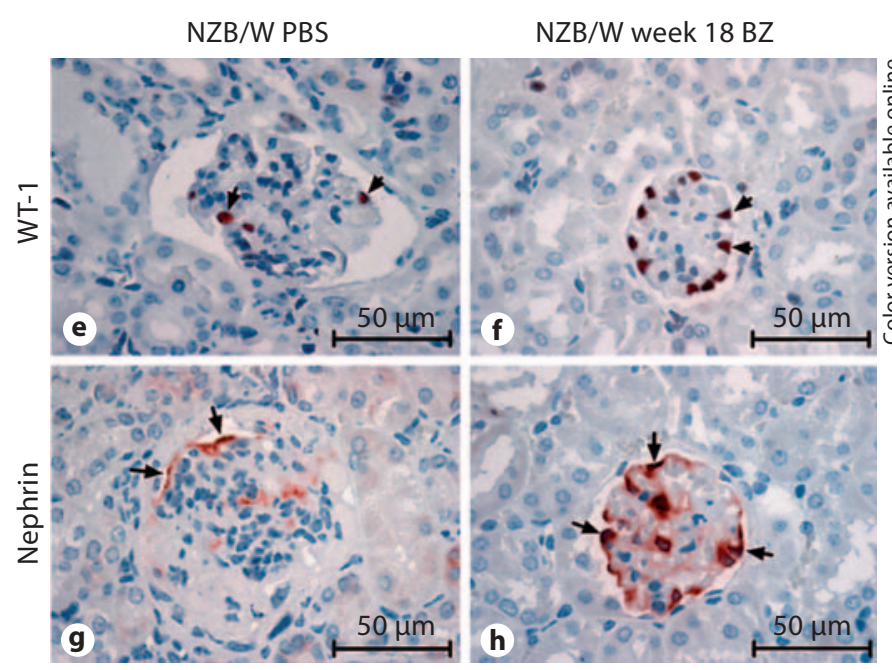

pression of podocyte markers WT-1 (e, f, red-brown staining) and nephrin $(\mathbf{g}, \mathbf{h})$ using immunohistological staining. Representative pictures of WT-1 expression in PBS-treated (e) and BZ-treated (f) animals are shown, demonstrating markedly higher WT-1 expression (examples of positive staining is marked by arrows) in glomeruli from PBS-treated compared to BZ-treated animals with experimental lupus nephritis. In addition, nephrin expression is nearly absent in PBS-treated NZB/W F1 mice on week 38 (g) but restored by BZ treatment (h) as shown here by representative microphotogaphs (arrows).
PBS-treated NZB/W F1 mice including the mouse surviving 15 months (in 2 mice necropsy was not possible) (fig. 4d). In contrast, kidneys of all BZ-treated mice showed either no pathology or just subtle signs of glomerular damage without evidence of tubulointerstitial and vascular changes (fig. $4 a-d$ ).

Proteasome Inhibition and Lupus Nephritis
Glomerular cell proliferation is typically increased in active lupus nephritis, as shown in the PBS-treated NZB/W F1 group. Mean glomerular volume and mean cell number per glomerulus were significantly lower in both BZ-treated groups as compared to PBS-treated NZB/W F1 mice (table 2). To investigate glomerular p27

Nephron Exp Nephrol 2012;120:e47-e58 


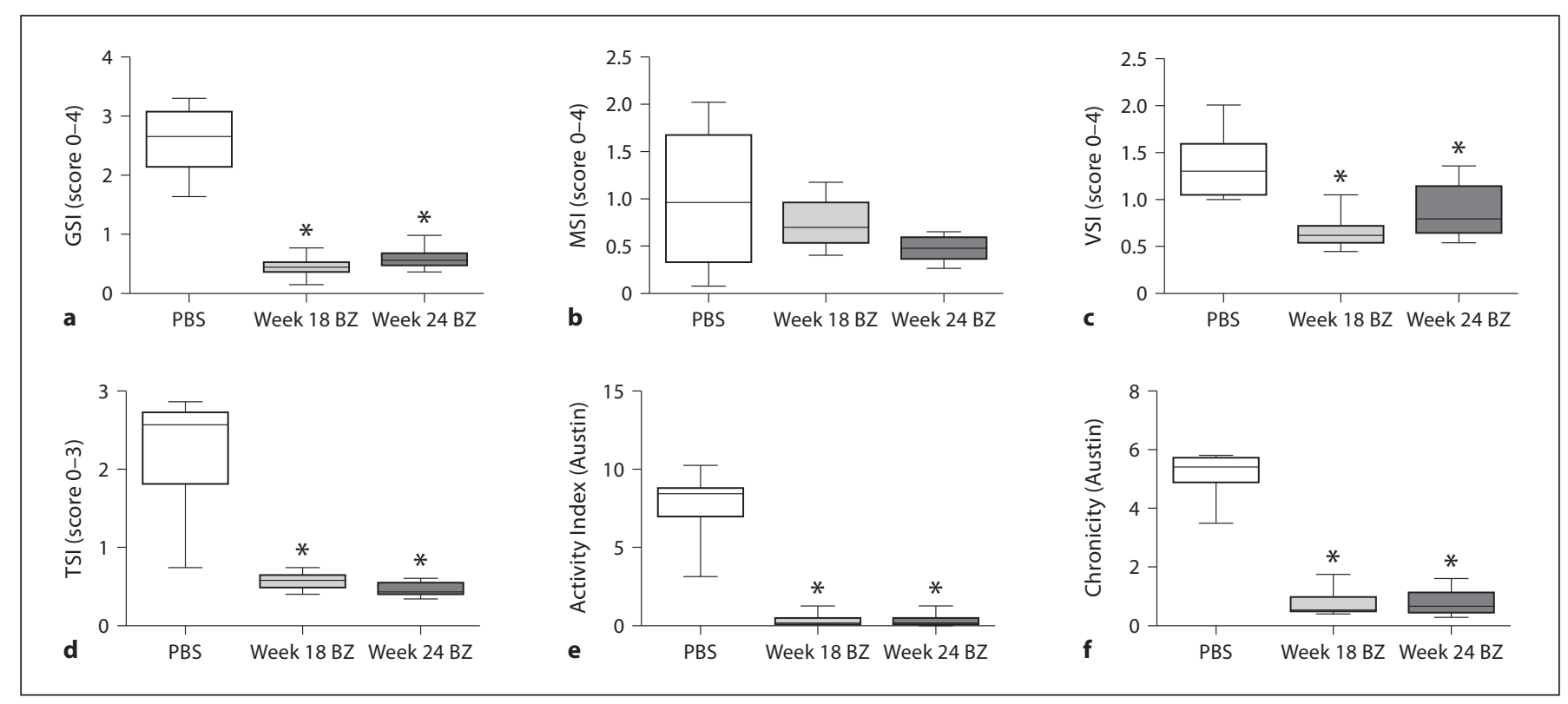

Fig. 4. Renal damage in NZB/W F1 mice is prevented by BZ treatment. Renal damage in NZB/W F1 mice was assessed by scoring glomerulosclerosis (a), mesangiolysis (b), vascular injury (c) and tubular injury (d). Furthermore, the activity (e) and chronicity (f) of lupus nephritis in the NZB/W F1 model was graded using the
Austin score. Except for mesangiolysis, BZ treatment prevented all investigated signs of renal damage in NZB/W F1 mice at the end of the experiment. ${ }^{*}$ Statistically significant differences between PBS- and BZ-treated groups $(\mathrm{p}<0.01)$.

Table 2. Renal pathology in PBS-treated and BZ-treated NZB/W mice

\begin{tabular}{|c|c|c|c|c|}
\hline & \multicolumn{3}{|l|}{ NZB/W } & \multirow{2}{*}{$\begin{array}{l}\text { Kruskal-Wallis } \\
\text { H test }\end{array}$} \\
\hline & PBS & week $18 \mathrm{BZ}$ & week 24 BZ & \\
\hline Glomerular convolute volume $\left(10^{3} \mu \mathrm{m}^{3}\right)$ & $222.5 \pm 16.6$ & $182.2 \pm 21.9$ & $163.5 \pm 12.16$ & $\mathrm{p}<0.01$ \\
\hline Total volume of glomerular capillaries $\left(10^{3} \mu \mathrm{m}^{3}\right)$ & $43.2 \pm 13.3$ & $87.5 \pm 11.9^{*}$ & $81.6 \pm 7.36^{*}$ & $\mathrm{p}<0.01$ \\
\hline Volume density of glomerular capillaries, $\%$ & $19.2 \pm 4.83^{*}$ & $48.1 \pm 3.74^{*}$ & $49.8 \pm 1.67^{*}$ & $\mathrm{p}<0.01$ \\
\hline Length density of glomerular capillaries, $\mathrm{mm} / \mathrm{mm}^{3}$ & $6,390 \pm 962$ & $14,087 \pm 883^{*}$ & $14,185 \pm 1,530^{*}$ & $\mathrm{p}<0.01$ \\
\hline MECA-positive vessels per medullar area & $494 \pm 501$ & $476 \pm 426$ & $637 \pm 441$ & n.s. \\
\hline MECA-positive vessels per cortical area & $208 \pm 223$ & $263 \pm 227$ & $211 \pm 157$ & n.s. \\
\hline Number of endothelial cells per glomerulus & $188 \pm 39.1$ & $110 \pm 26.7^{*}$ & $114 \pm 14.8^{*}$ & $\mathrm{p}<0.01$ \\
\hline Number of mesangial cells per glomerulus & $325 \pm 30.7$ & $180 \pm 30.0^{*}$ & $152 \pm 11.0^{*}$ & $\mathrm{p}<0.01$ \\
\hline Number of podocytes per glomerulus & $16.1 \pm 4.81$ & $30.8 \pm 3.31^{*}$ & $22.1 \pm 2.98^{*}$ & $\mathrm{p}<0.01$ \\
\hline
\end{tabular}

${ }^{*} \mathrm{p}<0.01$ vs. PBS-treated NZB/W using Dunn's multiple comparison posthoc test.

accumulation, as a potential mechanism for regulation of cell proliferation, kidneys were stained for cyclin-dependent kinase inhibitor p27. At the time point of analysis, when proliferative activity within the glomeruli was low, we found no evidence that glomerular p27 levels were altered by BZ treatment (fig. 7d). In agreement with this finding, glomerular cell proliferation (assessed as PCNA+ cells per glomerulus) was low and not different between the groups (fig. 5a). In contrast, tubular as well as interstitial cell proliferation was significantly lower in both BZ-treated groups than in PBS-treated NZB/W F1 mice (fig. 5b, c). The numbers of apoptotic cells as assessed by activated caspase- 3 staining were significantly higher in glomeruli of both BZ-treated groups compared to PBS- 

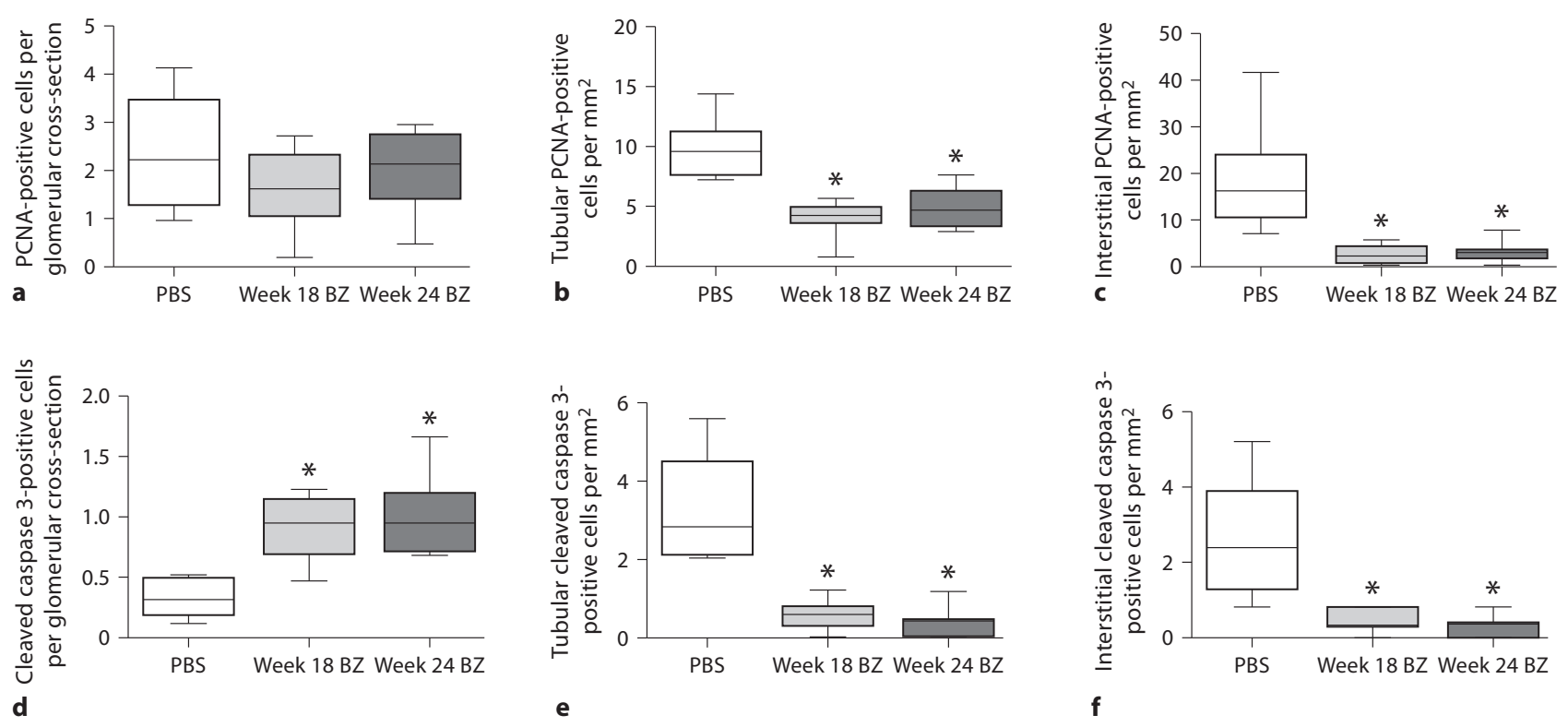

Fig. 5. Changes in proliferation and apoptosis of renal cells by BZtreatment. Renal proliferation was evaluated in glomerular crosssections (a), tubuli (b) and interstitial cells (c) by immunohistological staining for the proliferation marker PCNA. Glomerular (d), tubular (e) and interstitial (f) apoptosis was investigated by evaluation of immunostaining of cells positive for cleaved caspase-3. * Statistically significant differences between PBS- and BZ-treated groups ( $\mathrm{p} \leq 0.001)$. treated NZB/W F1 mice (fig. 5d), whereas in the tubuli and interstitium the numbers were significantly lower (fig. 5e, f). Interestingly, these data indicate a specific effect of BZ on glomerular, but not on tubular or interstitial cell apoptosis and proliferation. Matrix accumulation, as assessed by staining for collagen IV expression, was markedly reduced in the glomerular and interstitial compartments by BZ treatment (fig. 6a, b). Representative microphotographs show massive collagen IV accumulation in the PBS-treated NZB/W F1 mice (fig. 6c) but only basal expression in BZ-treated mice (fig. 6d). Of note, peritubular capillarization as assessed by MECA-positive vessels per medullar and cortical area was not significantly different between the 3 groups (table 2).

Using WT-1, synaptopodin and nephrin as podocytespecific markers, we investigated specific effects of BZ on podocytes which are known to be involved in proteasomal function. We found a significantly higher number of WT- $1^{+}$cells as well as marked preservation of nephrin and synaptopodin expression in BZ-treated NZB/W F1 mice compared to PBS-treated NZB/W F1 animals indicating podocyte preservation and survival by BZ (fig. $3 \mathrm{e}-$ h; fig. $7 \mathrm{a}-\mathrm{c}$ ). Glomerular nuclear expression of activated NF- $\mathrm{KB}$ the activation of which depends primarily on
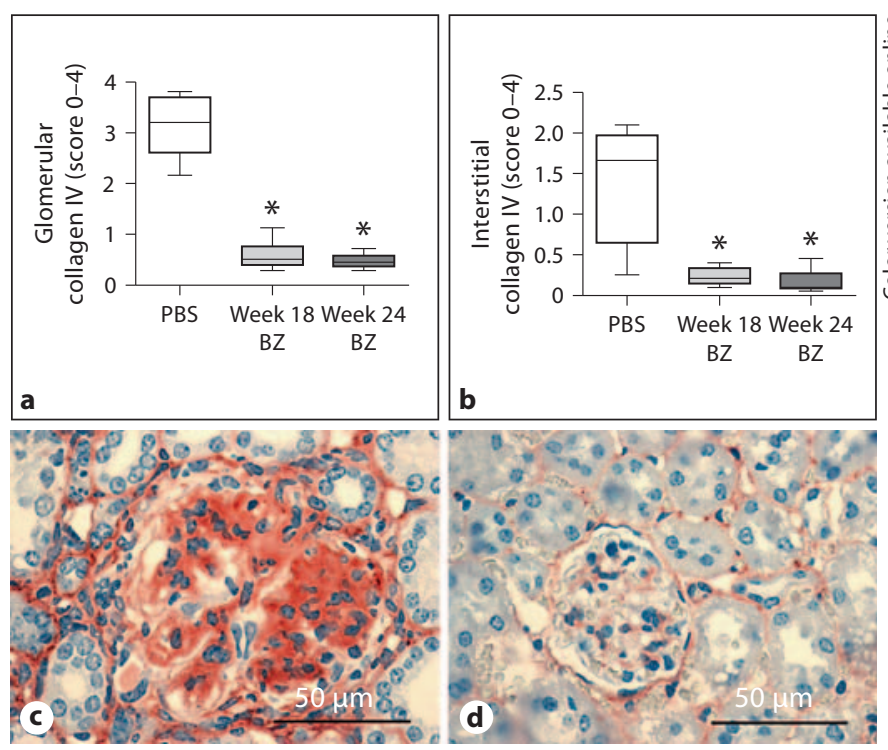

Fig. 6. Changes in renal matrix accumulation by BZ treatment. Matrix accumulation was measured by semiquantitative scoring of collagen IV expression as assessed by immunohistochemistry in glomerular cross-sections (a) and in the interstitium (b). Representative microphotographs from glomeruli of NZB/W F1 mice treated with PBS (c, brown staining) or BZ starting on week 18 (d). * Statistically significant differences between PBS- and BZ-treated groups ( $\mathrm{p} \leq 0.001)$. 
Fig. 7. Podocytes are preserved in NZB/W $\mathrm{F} 1$ mice treated with $\mathrm{BZ}$. In BZ-treated NZB/W F1 mice (light and dark gray columns) 3 different markers for podocytes, nephrin (a), WT-1 (b) and synaptopodin (c), were expressed significantly higher compared to PBS-treated NZB/W F1 mice with lupus nephritis. In contrast, no differences in the expression of the cyclindependent kinase inhibitor p27 was observed (d).

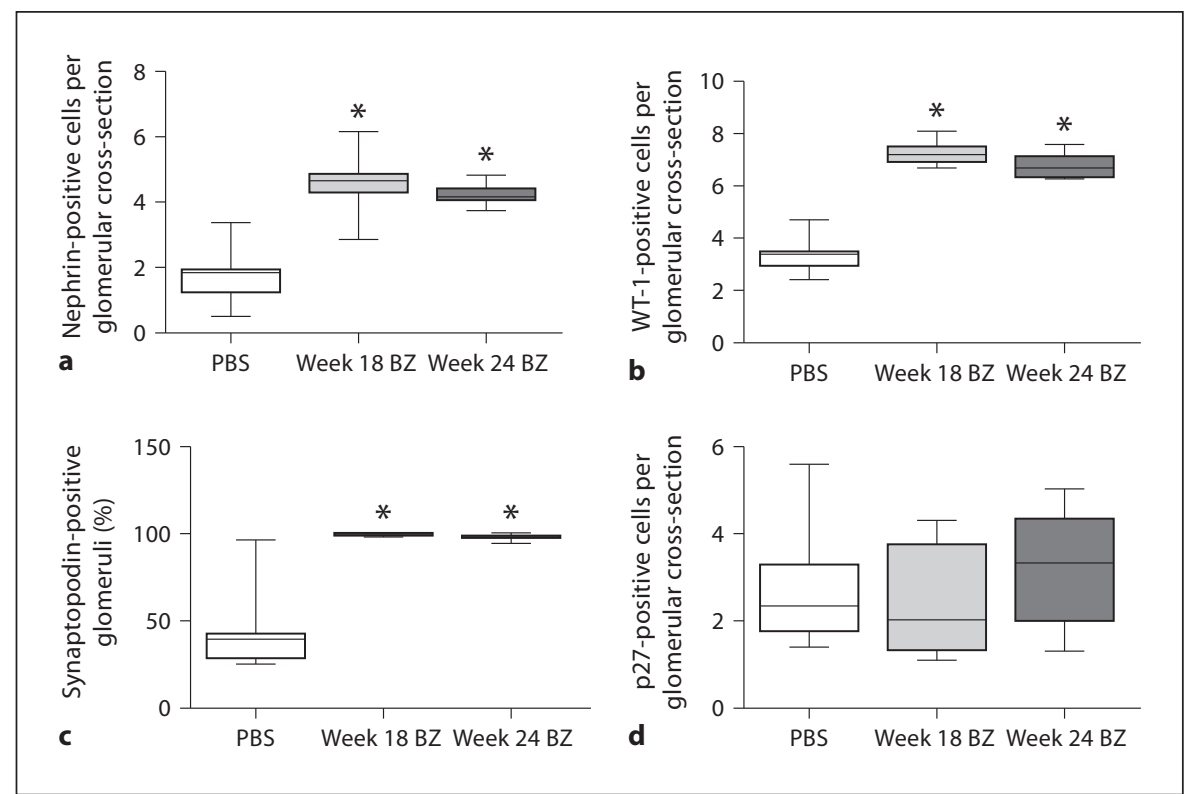

proteasome activity, was significantly lower in BZtreated groups compared to PBS-treated NZB/W F1 mice (fig. 3c, d).

Immunohistochemistry using an anti-IgG antibody revealed marked membranous and subendothelial IgGdepositions and occasional staining of glomerular capillary walls of PBS-treated animals. In contrast, no or only minimal IgG depositions in glomeruli of mice treated with BZ from 18 or 24 weeks of age (data shown previously [17]) were seen.

Changes of glomerular cells and capillaries were investigated using semithin sections (fig. $8 \mathrm{a}, \mathrm{b}$ ). We found significantly more mesangial matrix in parallel with lower capillary surface area and capillary volume in glomeruli of PBS-treated mice (fig. 8a) compared to BZtreated mice (fig. 8b). In particular, length density of glomerular capillaries, i.e. the length of all capillaries per unit glomerular volume, was significantly higher (220.5 and $221.0 \%$, respectively) in both BZ-treated groups compared to PBS-treatment.

The number of mesangial and endothelial cells per glomerulus was significantly lower and the podocyte number significantly higher in both BZ-treated groups than in PBS-treated NZB/W F1 mice (table 2). Of note, the podocyte number was even slightly higher in the early compared to the late BZ treatment group. In parallel, mean volumes of all 3 cell types were not altered (data not shown).
On electron microscopy, marked thickening of the glomerular basement membrane (fig. 8e, BM) together with large subendothelial osmiophilic deposits (fig. 8e, OSD), swelling of endothelial cells (fig. 8c, EC), enlarged podocytes (fig. 8c, PC) with increased cytoplasmic vacuolization (fig. 8c, white asterisk) and foot process effacement (fig. 8c, arrows) were seen in PBS-treated NZB/W F1 mice. In addition, mesangial cell and matrix expansion could be found (fig. 8a). These ultrastructural changes were completely prevented by BZ treatment regimens (fig. $8 \mathrm{~b}, \mathrm{~d}, \mathrm{f}$ ).

\section{Discussion}

In this study early and late treatment of experimental lupus nephritis in NZB/W F1 mice by the proteasome inhibitor BZ markedly improved renal pathology and survival. Since exact analysis of BZ effects on renal cells was lacking in this animal model for lupus nephritis, we performed detailed morphological and ultrastructural analyses. Our data indicate the effects of BZ treatment on renal cells, in particular on podocyte structure and function, as well as on glomerular cell apoptosis. In parallel, interstitial damage and particularly interstitial cell proliferation was significantly prevented by BZ. Elimination of anti-dsDNA antibody-secreting plasma cells by BZ treatment is an important mechanism by which $\mathrm{BZ}$ pro- 


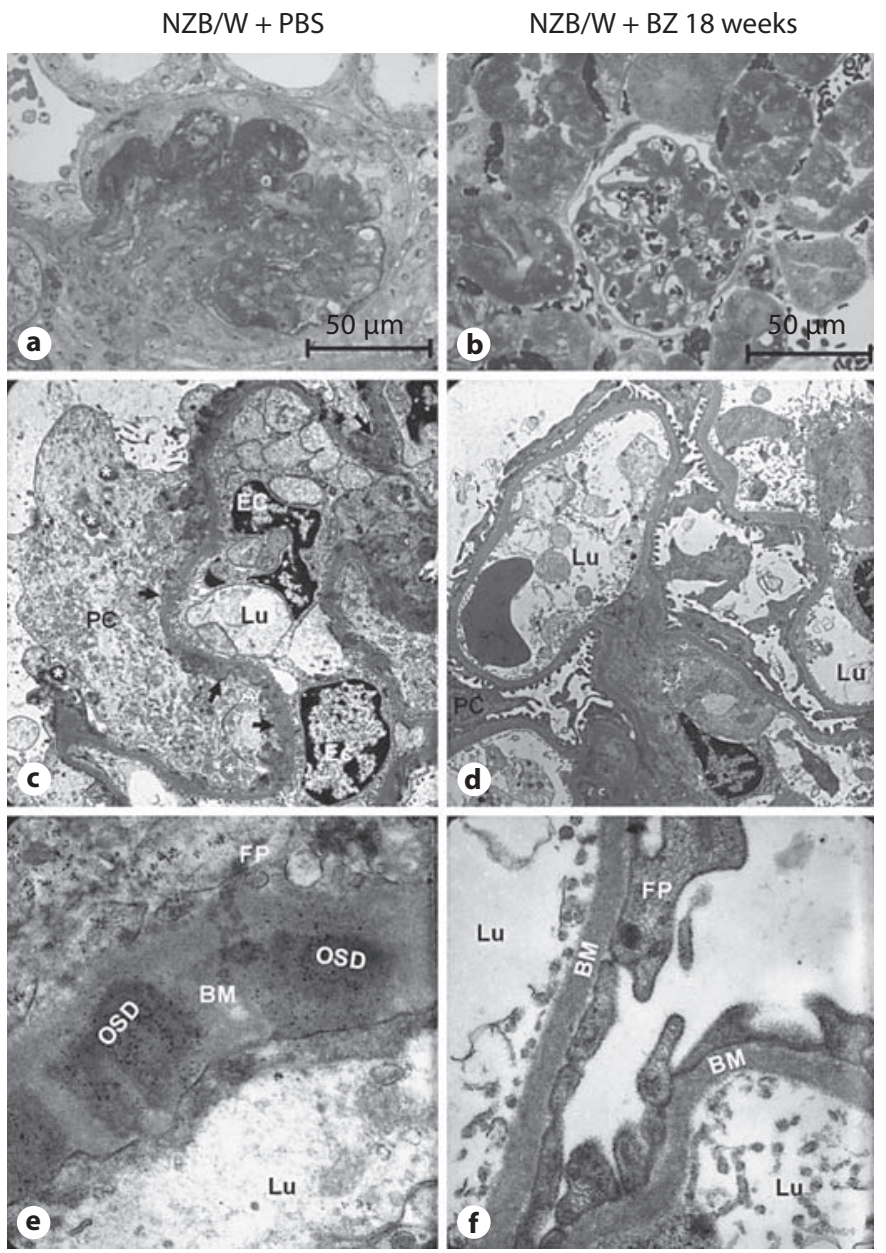

Fig. 8. Ultrastructural changes in NZB/W F1 mice treated with $\mathrm{PBS}$ or BZ. In NZB/W F1 mice glomeruli show pronounced glomerulosclerosis with degenerative changes of podocytes in PBStreated (a) but not in BZ-treated (b) semithin sections using PAS staining. $\times 1,000$. c Using electron microscopy, glomeruli from PBS-treated NZB/W F1 mice showed enlarged podocytes (PC) with increased cytoplasmic vacuolization (white asterisk) and foot process effacement (arrows), as well as swelling of endothelial cells (EC). d Preserved glomerular ultrastructure of a BZtreated NZB/W F1 mouse. e Glomerular basement membrane (BM) was thickened and shows intramembranous and subendothelial osmiophilic deposits (OSD). $\mathbf{f}$ The glomerular basement membrane is intact in BZ-treated NZB/W F1 mice, showing also intact foot processes (FP). For a better orientation the capillary lumina $(\mathrm{Lu})$ are indicated. Electron microscopy. c, $\mathbf{d} \times 4,646$. e, f $\times 27,800$.

tects the kidney in experimental SLE [17]. Our findings suggest that in addition to this systemic effect there may also be specific glomerular and tubulointerstitial targets of BZ. This is in line with in vitro findings in glomerular as well as tubular cells showing direct effects of protea- some inhibitor treatment $[24,25]$. High apoptosis rates were induced by BZ in isolated mesangial cells [25]. In our study we also detected increased apoptosis rates of glomerular cells in BZ-treated NZB/W F1 mice. This may be due to high sensibility of mesangial cells to BZ. The effects of BZ on other glomerular cells like podocytes have not been reported so far. Of note, in our study BZ specifically prevented podocyte damage and loss as indicated by WT-1, nephrin and synaptopodin staining, and ultrastructural analysis. Therefore, we would like to postulate potential podocyte-specific effects of $\mathrm{BZ}$ in experimental lupus nephritis.

Activation of UPR is regarded as the main mechanism for myeloma and plasma cell depletion by proteasome inhibition [16]. This effect, however, is dependent on the cellular synthesis rate for secretory proteins such as immunoglobulins. The UPR is important for cellular survival and homeostasis mediated by the induction of chaperons such as binding and heat shock proteins [26, 27]. However, overwhelming endoplasmic reticulum stress induces the UPR leading to activation of caspases and apoptotic cell death [28]. This mechanism was first demonstrated in myeloma cells $[13,16]$ and also confirmed for primary plasma cells [17]. Since the proteasome is ubiquitously involved in protein degradation it seems plausible that the glomerular filtration barrier, which is charged by a lot of filtered proteins, is also well equipped with the proteasome machinery. This idea is further substantiated since podocytes have recently been shown to express UCHL-1 [29], an important component of the proteasome machinery. An inhibitory effect of TGF- $\beta$ on proteasomal degradation of the cyclin-dependent kinase inhibitor p27 has also been described [30]. $\mathrm{BZ}$ was shown to arrest the proliferation of hepatocellular carcinoma cells by differentially affecting p21 and p27 levels [31]. In addition, BZ treatment also significantly increased p21 mRNA in an ischemia/reperfusion model [32]. The p21 and p27 proteins are important regulators of cell cycle in glomerular cells [33] and lack of p27 was shown to protect from diabetic nephropathy [34]. In our study, however, we could not detect any effect of BZ on p27 expression by immunohistochemistry. A potential effect of $\mathrm{BZ}$ on p27 expression in the present study cannot be definitely excluded, since proliferative activity in this SLE model was low at the time point investigated.

Another major mechanism of $\mathrm{BZ}$ action is the blockade of the key transcription factor NF- $\kappa \mathrm{B}$ which is important for the survival of many cells by inducing several antiapoptotic genes $[35,36]$. In addition, NF- $\kappa B$ plays a 
considerable role in the immune and inflammatory response. Since activation of NF- $\kappa \mathrm{B}$ is dependent primarily on proteasomal cleavage of its inhibitor proteins (IкBs), proteasome inhibition may account for the relatively low amounts of activated nuclear NF- $\kappa B$ detectable in the BZ-treated animals. We detected relatively large amounts of activated NF- $\kappa B$ in the nuclei of glomerular cells of untreated nephritic NZB/W F1 mice, whereas nuclear NF- $\kappa \mathrm{B}$ was rarely detectable in BZ-treated mice. This lower NF- $\kappa \mathrm{B}$ activity could be directly caused by proteasome inihibition. Upon degradation of ІкBs, NF$\kappa \mathrm{B}$ is released and translocated into the nucleus where it regulated genes including proinflammatory mediators like TNF- $\alpha$, IL-1 and IL- 6 as well as intercellular adhesion molecules like ICAM-1.

Activation of NF- $\kappa \mathrm{B}$ was shown in endothelial, mesangial cells as well as in podocytes of patients with lupus nephritis and correlated with the degree of proteinuria [37]. In addition, activation of proinflammatory proteins was found in glomerular cells [38] and NF- $\kappa$ B activation was shown to correlate well with the activity index of lupus nephritis, ICAM-1 expression and glomerular macrophage invasion [39]. These data suggest that NF- $\kappa \mathrm{B}$ activation in glomerular cells by proinflammatory effects is presumably mediated by mesangial cell-macrophage interaction. There is some evidence that NF- $\kappa \mathrm{B}$ activation and increased cytokine expression induces activation and structural remodeling of the podocytes [40]. This may also be the case in our experimental study in which inhibition of proteasome activity, i.e. indirect blockade of the NF- $\kappa \mathrm{B}$ effect, can prevent structural and presumably also functional damage of the podocytes.

In addition, it has been shown that one of the most important structural proteins of the podocytes, $\alpha$-actinin-4, is degraded by the proteasome [41, 42]. Mutations of $\alpha$-actinin- 4 are thought to be responsible for an inherited form of focal segmental glomerulosclerosis [43] demonstrating the particular importance of this protein. It is thus conceivable that proteasome inhibition by BZ could preserve podocyte structure by inhibiting the loss of the cytoskeleton by lower $\alpha$-actinin- 4 degradation. This mechanism may be also be operative for other podocytespecific proteins, i.e. WT-1, nephrin and synaptopodin. The expression of all 3 proteins was remarkably reduced in untreated NZB/W F1 mice but was preserved by treatment with BZ, indicating an effect of proteasome inhibition on podocyte structure and in particular on the slit diaphragm.
Apart from changes of glomerular structure in lupus nephritis there is also evidence of an important role of tubulointerstitial lesions in particular for the progression of the disease [44]. Of note, in our study proteasome inhibition by BZ significantly prevented tubulointerstitial damage as indicated by tubular dilatation, tubular atrophy, interstitial inflammation and interstitial fibrosis. Most remarkably and in contrast to the results for glomerular cells, the increased proliferation rate of tubulointerstitial cells in untreated NZB/W F1 mice was completely prevented in both BZ-treated groups. Despite not finding any difference in the proliferative activity of glomerular cells at the end of the study, significantly lower glomerular cell numbers suggest that glomerular proliferation is also affected by BZ treatment. In addition, tubular apoptosis, as assessed by cleaved caspase-3 staining, is markedly decreased by BZ treatment. This is consistent with studies in vitro showing low apoptosis rates after BZ treatment due to the induction of survival signals in isolated tubular cells [25]. Another potential mechanism for how BZ can prevent tubular apoptosis is described in a model of cisplatin nephrotoxicity, showing the blocking of caspase activation and mitochondrial release of apoptosis-inducing factor [45].

We have to acknowledge, however, that treatment with the proteasome inhibitor BZ also leads to systemic effects, i.e. significantly lower anti-dsDNA antibody levels during the course of the treatment which may also contribute to the amelioration of nephritis in this animal model. In addition, proteasome inhibition prevents the processing of antigenic peptides [46], which is important in the generation of pathogenic antibodies.

However, other studies on the effects of proteasome inhibition showed either beneficial $[24,25,45,47-49]$ or adverse effects $[25,32]$ on the kidney or kidney cells. Therefore, treatment with BZ must be performed with great caution because renal cellular function is obviously modulated by BZ in a cell-type-specific manner and is dependent on the injury and dose of BZ.

In summary, our findings in an animal model of lupus nephritis argue for beneficial effects of proteasome inhibition on the development of diffuse proliferative nephritis. Most likely, this extensive effect is mediated by both a systemic effect of $\mathrm{BZ}$ on antibody production by plasma cells as well as a specific renal effect on podocytes and tubulointerstitial cells. The renal effects of $\mathrm{BZ}$ might be partly mediated by NF- $\kappa$ B inhibition and partly by interference with other proteasome-dependent pathomechanisms acting in podocytes. The results of the present ex- 
perimental study may also indicate new treatment options for patients with progressive lupus nephritis which are resistant to conventional immunosuppressive therapy.

If our hypothesis that $\mathrm{BZ}$ prevents deterioration of glomerular structures in immune-mediated renal disease holds true, proteasome inhibition could very well open new therapeutic avenues for several forms of inflammatory kidney disease and clinical trials should be initiated.

\section{Acknowledgements}

The study was supported by the Interdisciplinary Center for Clinical Research (IZKF, project No. N2, N3, A11, A31 and J4) and the German Research Society (FOR 832, project 8 [VO673/31] and Collaborative Research Centers SFB 643; project B3, both to Reinhard Voll, and SFB 423, project Z2 to Kerstin Amann. The technical assistance of M. Klewer, M. Reutelshöfer and K. Schmitt is gratefully acknowledged.

\section{Disclosure Statement}

\section{References}

1 Lipsky PE: Systemic lupus erythematosus: an autoimmune disease of B cell hyperactivity. Nat Immunol 2001;2:764-766.

2 Mills JA: Systemic lupus erythematosus. N Engl J Med 1994;330:1871-1879.

3 Manz RA, Radbruch A: Plasma cells for a lifetime? Eur J Immunol 2002;32:923-927.

4 Miller JJ 3rd, Cole LJ: Resistance of longlived lymphocytes and plasma cells in rat lymph nodes to treatment with prednisone, cyclophosphamide, 6 mercaptopurine and actinomycin D. USNRDL-TR-67-24. Res Dev Tech Rep 1967;11:1-20.

5 Slifka MK, Ahmed R: Long-lived plasma cells: a mechanism for maintaining persistent antibody production. Curr Opin Immunol 1998;10:252-258.

6 Theofilopoulos AN, Dixon FJ: Murine models of systemic lupus erythematosus. Adv Immunol 1985;37:269-390.

7 Cassese G, Lindenau S, de Boer B, Arce S, Hauser A, Riemekasten G, Berek C, Hiepe F, Krenn V, Radbruch A, Manz RA: Inflamed kidneys of NZB/W mice are a major site for the homeostasis of plasma cells. Eur J Immunol 2001;31:2726-2732.

8 Hoyer BF, Moser K, Hauser AE, Peddinghaus A, Voigt C, Eilat D, Radbruch A, Hiepe F, Manz RA: Short-lived plasmablasts and long-lived plasma cells contribute to chronic humoral autoimmunity in NZB/W mice. J Exp Med 2004;199:1577-1584.

9 van Tol MJ, Gerritsen EJ, de Lange GG, van Leeuwen AM, Jol-van der Zijde CM, Oudeman-Gruber NJ, de Vries E, Radl J, Vossen JM: The origin of IgG production and homogeneous IgG components after allogeneic bone marrow transplantation. Blood 1996; $87: 818-826$

10 Ang HA, Apperley JF, Ward KN: Persistence of antibody to human parvovirus B19 after allogeneic bone marrow transplantation: role of prior recipient immunity. Blood 1997; 89:4646-4651.
11 Adams J: The proteasome: a suitable antineoplastic target. Nat Rev Cancer 2004;4: 349-360.

12 Hideshima T, Richardson PG, Anderson KC: Targeting proteasome inhibition in hematologic malignancies. Rev Clin Exp Hematol 2003; 7:191-204.

13 Meister S, Schubert U, Neubert K, Herrmann K, Burger R, Gramatzki M, Hahn S, Schreiber S, Wilhelm S, Herrmann M, Jack HM, Voll RE: Extensive immunoglobulin production sensitizes myeloma cells for proteasome inhibition. Cancer Res 2007;67: 1783-1792.

14 Rajkumar SV, Richardson PG, Hideshima T, Anderson KC: Proteasome inhibition as a novel therapeutic target in human cancer. J Clin Oncol 2005;23:630-639.

15 Maseda D, Meister S, Neubert K, Herrmann M, Voll RE: Proteasome inhibition drastically but reversibly impairs murine lymphocyte development. Cell Death Differ 2008; 15 : 600-612

16 Obeng EA, Carlson LM, Gutman DM, Harrington WJ Jr, Lee KP, Boise LH: Proteasome inhibitors induce a terminal unfolded protein response in multiple myeloma cells. Blood 2006;107:4907-4916.

17 Neubert K, Meister S, Moser K, Weisel F, Maseda D, Amann K, Wiethe C, Winkler TH, Kalden JR, Manz RA, Voll RE: The proteasome inhibitor bortezomib depletes plasma cells and protects mice with lupus-like disease from nephritis. Nat Med 2008; 14 : 748-755.

18 Wellmann U, Letz M, Schneider A, Amann $\mathrm{K}$, Winkler TH: An Ig mu-heavy chain transgene inhibits systemic lupus erythematosus immunopathology in autoimmune (NZB $x$ NZW)F1 mice. Int Immunol 2001;13:14611469.

19 Haas CS, Amann K, Schittny J, Blaser B, Muller U, Hartner A: Glomerular and renal vascular structural changes in alpha8 integrin-deficient mice. J Am Soc Nephrol 2003; 14:2288-2296.
20 el Nahas AM, Bassett AH, Cope GH, Le Carpentier JE: Role of growth hormone in the development of experimental renal scarring. Kidney Int 1991;40:29-34.

21 Goumenos DS, Brown CB, Shortland J, el Nahas AM: Myofibroblasts, predictors of progression of mesangial IgA nephropathy? Nephrol Dial Transplant 1994;9:1418-1425.

22 Dimmler A, Haas CS, Cho S, Hattler M, Forster C, Peters H, Schocklmann HO, Amann $\mathrm{K}$ : Laser capture microdissection and realtime PCR for analysis of glomerular endothelin-1 gene expression in mesangiolysis of rat anti-Thy 1.1 and murine Habu snake venom glomerulonephritis. Diagn Mol Pathol 2003;12:108-117.

23 Austin HA 3rd, Muenz LR, Joyce KM, Antonovych TA, Kullick ME, Klippel JH, Decker JL, Balow JE: Prognostic factors in lupus nephritis - contribution of renal histologic data. Am J Med 1983;75:382-391.

24 Bush KT, Goldberg AL, Nigam SK: Proteasome inhibition leads to a heat-shock response, induction of endoplasmic reticulum chaperones, and thermotolerance. J Biol Chem 1997;272:9086-9092.

25 Sarkozi R, Perco P, Hochegger K, Enrich J, Wiesinger M, Pirklbauer M, Eder S, Rudnicki M, Rosenkranz AR, Mayer B, Mayer G, Schramek H: Bortezomib-induced survival signals and genes in human proximal tubular cells. J Pharmacol Exp Ther 2008;327: 645-656.

26 Gass JN, Gifford NM, Brewer JW: Activation of an unfolded protein response during differentiation of antibody-secreting B cells. J Biol Chem 2002;277:49047-49054.

27 Iwakoshi NN, Lee AH, Vallabhajosyula P, Otipoby KL, Rajewsky K, Glimcher LH: Plasma cell differentiation and the unfolded protein response intersect at the transcription factor XBP-1. Nat Immunol 2003;4:321329.

28 Liu CY, Kaufman RJ: The unfolded protein response. J Cell Sci 2003;116:1861-1862. 
29 Liu Y, Wu J, Wu H, Wang T, Gan H, Zhang X, Liu Y, Li R, Zhao Z, Chen Q, Guo M, Zhang Z: UCH-L1 expression of podocytes in diseased glomeruli and in vitro. J Pathol 2009;217:642-653.

30 Lecanda J, Ganapathy V, D'Aquino-Ardalan C, Evans B, Cadacio C, Ayala A, Gold LI: TGFbeta prevents proteasomal degradation of the cyclin-dependent kinase inhibitor p27kip1 for cell cycle arrest. Cell Cycle 2009; 8:742-756.

31 Baiz D, Pozzato G, Dapas B, Farra R, Scaggiante $B$, Grassi M, Uxa L, Giansante C, Zennaro C, Guarnieri G, Grassi G: Bortezo$\mathrm{mib}$ arrests the proliferation of hepatocellular carcinoma cells HepG2 and JHH6 by differentially affecting E2F1, p21 and p27 levels. Biochimie 2009;91:373-382.

32 Huber JM, Tagwerker A, Heininger D, Mayer G, Rosenkranz AR, Eller K: The proteasome inhibitor bortezomib aggravates renal ischemia-reperfusion injury. Am J Physiol Renal Physiol 2009;297:F451-F460.

33 Al-Douahji M, Brugarolas J, Brown PA, Stehman-Breen CO, Alpers CE, Shankland SJ: The cyclin kinase inhibitor p21WAF1/ CIP1 is required for glomerular hypertrophy in experimental diabetic nephropathy. Kidney Int 1999;56:1691-1699.

34 Wolf G, Schanze A, Stahl RA, Shankland SJ, Amann K: p27(Kip1) knockout mice are protected from diabetic nephropathy: evidence for p27(Kip1) haplotype insufficiency. Kidney Int 2005;68:1583-1589.

35 Ko BS, Chang TC, Chen CH, Liu CC, Kuo CC, Hsu C, Shen YC, Shen TL, Golubovskaya VM, Chang CC, Shyue SK, Liou JY: Bortezomib suppresses focal adhesion kinase expression via interrupting nuclear factor-kappa B. Life Sci 2010;86:199-206.
36 Russo A, Bronte G, Fulfaro F, Cicero G, Adamo V, Gebbia N, Rizzo S: Bortezomib: a new pro-apoptotic agent in cancer treatment. Curr Cancer Drug Targets 2010;10:55-67.

37 Zheng L, Sinniah R, Hsu SI: Renal cell apoptosis and proliferation may be linked to nuclear factor-kappaB activation and expression of inducible nitric oxide synthase in patients with lupus nephritis. Hum Pathol 2006;37:637-647.

38 Ashizawa M, Miyazaki M, Abe K, Furusu A, Isomoto $\mathrm{H}$, Harada $\mathrm{T}$, Ozono $\mathrm{Y}$, Sakai $\mathrm{H}$, Koji T, Kohno S: Detection of nuclear factor-kappaB in IgA nephropathy using southwestern histochemistry. Am J Kidney Dis 2003;42: 76-86.

39 Mudge SJ, Paizis K, Auwardt RB, Thomas RJ, Power DA: Activation of nuclear factor-kappa $B$ by podocytes in the autologous phase of passive Heymann nephritis. Kidney Int 2001;59:923-931.

40 Abbate M, Zoja C, Morigi M, Rottoli D, Angioletti S, Tomasoni S, Zanchi C, Longaretti L, Donadelli R, Remuzzi G: Transforming growth factor-betal is up-regulated by podocytes in response to excess intraglomerular passage of proteins: A central pathway in progressive glomerulosclerosis. Am J Pathol 2002;161:2179-2193.

41 Cybulsky AV, Takano T, Papillon J, Bijian K, Guillemette J, Kennedy CR: Glomerular epithelial cell injury associated with mutant alpha-actinin-4. Am J Physiol Renal Physiol 2009;297:F987-F995.

42 Blattner SM, Kretzler M: Integrin-linked kinase in renal disease: connecting cell-matrix interaction to the cytoskeleton. Curr Opin Nephrol Hypertens 2005; 14:404-410.
43 Kaplan JM, Kim SH, North KN, Rennke H, Correia LA, Tong HQ, Mathis BJ, RodriguezPerez JC, Allen PG, Beggs AH, Pollak MR: Mutations in ACTN4, encoding alpha-actinin-4, cause familial focal segmental glomerulosclerosis. Nat Genet 2000;24:251256.

44 D'Amico G: Tubulointerstitium as predictor of progression of glomerular diseases. Nephron 1999;83:289-295.

45 Liu L, Yang C, Herzog C, Seth R, Kaushal GP: Proteasome inhibitors prevent cisplatin-induced mitochondrial release of apoptosisinducing factor and markedly ameliorate cisplatin nephrotoxicity. Biochem Pharmacol 2010;79:137-146.

46 Macconi D, Chiabrando C, Schiarea S, Aiello S, Cassis L, Gagliardini E, Noris M, Buelli S, Zoja C, Corna D, Mele C, Fanelli R, Remuzzi $\mathrm{G}$, Benigni A: Proteasomal processing of albumin by renal dendritic cells generates antigenic peptides. J Am Soc Nephrol 2009;20: 123-130.

47 Itoh M, Takaoka M, Shibata A, Ohkita M, Matsumura Y: Preventive effect of lactacystin, a selective proteasome inhibitor, on ischemic acute renal failure in rats. J Pharmacol Exp Ther 2001;298:501-507.

48 Takaoka M, Itoh M, Kohyama S, Shibata A, Ohkita M, Matsumura Y: Proteasome inhibition attenuates renal endothelin-1 production and the development of ischemic acute renal failure in rats. J Cardiovasc Pharmacol 2000;36:S225-S227.

49 Takaoka M, Ohkita M, Itoh M, Kobayashi Y, Okamoto H, Matsumura Y: A proteasome inhibitor prevents vascular hypertrophy in deoxycorticosterone acetate-salt hypertensive rats. Clin Exp Pharmacol Physiol 2001; 28:466-468. 